\title{
Acinetobacter baumannii as Nosocomial Pathogenic Bacteria
}

\author{
Fariba Akrami $^{a}$ and Amirmorteza Ebrahimzadeh Namvar ${ }^{a, *}$ \\ ${ }^{a}$ Department of Microbiology, Faculty of Medicine, Babol University of Medical Sciences, Babol, Iran \\ *e-mail: Amirmorteza.namvar@gmail.com \\ Received May 27, 2018; revised May 27, 2018; accepted October 15, 2018
}

DOI: $10.3103 / \mathrm{S} 0891416819020046$

\section{INTRODUCTION AND NATURAL HABITAT}

The Acinetobacter genus has emerged as a nosocomial infection with a wide range of mortality and morbidity in recent years. Although this microorganism which was isolated from clinical samples in the 1970s, still known as an opportunistic bacteria [1]. The bacterial taxonomy is as follow: Bacteria; Proteobacteria; Gammaproteobacteria; Pseudomonadales; Moraxellaceae, Genus: Acinetobacter. The distinguished variant species by Bouvet and Grimont are including as: Acinetobacter baumannii, Acinetobacter calcoaceticus, Acinetobacter haemolyticus, Acinetobacter johnsonii, Acinetobacter jejuni and Acinetobacter lwoffii [2-4]. The Acinetobacter genus consists of $A$. calcoaceticus, Acinetobacter genomic species 3 and Acinetobacter species TU13. These species are very similar but the phenotypic characterization is extremely difficult. Later on, it was also suggested that these species may be categorized in Acinetobacter-calcoaceticus-Acinetobacter baumannii complex [5]. The other types of this bacterium that are called Acinetobacter parvus, Acinetobacter schindleri, Acinetobacter ursingii were isolated from the human body; and seven other strains, including Acinetobacter baylyi, Acinetobacter bouvetii, Acinetobacter grimontii, Acinetobacter tjernbergiae, Acinetobacter towneri, Acinetobacter tandoii, Acinetobacter gerneri have originated from the mud [6-8]. Currently it has been stated that Acinetobacter baumannii and related species, Acinetobacter nosocomialis and Acinetobacter pittii (Acinetobacter baumannii complex) are regarded as a wide range of clinical infections. Acinetobacter variabilis was discovered recently by Krizova [7]. The genomic species 3 and TU13 were respectively replaced by Acinetobacter nosocomialis and Acinetobacter pittii $[8,9]$. A number of the Acinetobacter genus, for example $A$. johnsonii, $A$. lwoffii and $A$. radioresistens are found on the skin normal flora especially in tropical inhabitants [10]. In contrast, A. baumannii is also isolated from hospitalized patients and environments however, can be colonized about 41 percent in intensive care unit patients [11, 12]. Another group that consists of antibiotic sensitive cluster (A. johnsonii and $A$. calcoaceticus) is obtained from environmental resources, soil and contaminated waters. According to several studies, the most members of the last two groups have carbapenem resistance genes [13].

\section{EPIDEMIOLOGY AND DISEASES}

Patients are the primary source of infection which can spread the bacteria through clinical environment, medical equipment and hospital staff. In addition, Acinetobacter incidence infections can be influenced by person to person contact and bacterial resistance to antibiotics and disinfectants [14, 15]. Since the 1980s, the prevalence of bacteria has been reported across the world, encompass Europe, especially the UK, Germany, Italy, Spain and United States by transmission of multi-drug resistant strains [16, 17]. Many studies in North America have indicated the emergence of multidrug resistant strains. Acinetobacter nosocomial infections are in relation with seasonal infectious diseases, particularly with summer. The highest rate of resistance to imipenem, meropenem, ceftazidime, ciprofloxacin, piperacillin-tazobactam and gentamicin has been observed in Latin America [18]. As a result of conducted studies in Asian countries, most of bacteria, isolated from acquired pneumonia (13.6\%) and ventilator-associated pneumonia $(36.5 \%)$, were belonged to Acinetobacter species. Acinetobacter has more dispersion in China compare to Thailand and Malaysia [19]. The frequency of carbapenem-resistant Acinetobacter strains in India was stated to be nearly 35 percent $[20,21]$. According to statistics published by $\mathrm{ECDC}^{1}$, the resistance rate of carbapenem in Acinetobacter strains has been reached up to $25 \%$. The prevalence of Acinetobacter among nosocomial infections in Bosnia was $51.4 \%$, in which $74.1 \%$ were belonged to respiratory infections [22]. Although the rate of multi-drug resistant strains of Acinetobacter is almost $30 \%$ in Italy [23]. In general, researches show that the community-acquired bacterial infections are often detected in tropical and subtropical regions such as Singapore, Hong Kong, and Taiwan predominantly

\footnotetext{
${ }^{1}$ European Centre for Disease Prevention and Control.
} 
Table 1. Various genomic species of the genus Acinetobacter

\begin{tabular}{|c|c|c|c|}
\hline Species name & Genomic species no. & Type or representative strain & Major habitat or source \\
\hline A. baumannii & 2 & ATCC $19606^{\mathrm{T}}$ & Human clinical specimens \\
\hline A. baylyi & & DSM $14961^{\mathrm{T}}$ & Activated sludge, soil \\
\hline A. beijerinckii & & NIPH $838^{\mathrm{T}}$ & Soil, water \\
\hline A. bereziniae & 10 & ATCC $17924^{\mathrm{T}}$ & Human specimens, soil \\
\hline A. bouvetii & & DSM $14964^{\mathrm{T}}$ & Activated sludge \\
\hline A. calcoaceticus & 1 & ATCC $23055^{\mathrm{T}}$ & Soil, water \\
\hline A. gerneri & & DSM $14967^{\mathrm{T}}$ & Activated sludge \\
\hline A. grimontii & & DSM $14968^{\mathrm{T}}$ & Activated sludge \\
\hline A. guillouiae & 11 & ATCC $11171^{\mathrm{T}}$ & Human faeces, water, soil \\
\hline A. gyllenhergii & & NIPH $2150^{\mathrm{T}}$ & Human specimens \\
\hline A. haemolyticus & 4 & ATCC $17906^{\mathrm{T}}$ & Human specimens \\
\hline A. johnsonii & 7 & ATCC $17909^{\mathrm{T}}$ & Human skin, water, soil \\
\hline A. junii & 5 & ATCC $17908^{\mathrm{T}}$ & Human specimens \\
\hline A. lwoffii & $8 / 9$ & ATCC $15309^{\mathrm{T}}$ & Human skin \\
\hline A. parvus & & NIPH384 ${ }^{\mathrm{T}}$ & Humans and animals \\
\hline A. radioresistens & 12 & IAM $13186^{\mathrm{T}}$ & Human specimens, soil \\
\hline A. schindleri & & NIPH $1034^{\mathrm{T}}$ & Human specimens \\
\hline A. soli & & KCTC $22184^{\mathrm{T}}$ & Soil \\
\hline A. tandoii & & DSM $14970^{\mathrm{T}}$ & Activated sludge, soil \\
\hline A. tjernbergiae & & $\operatorname{DSM} 14971^{\mathrm{T}}$ & Activated sludge \\
\hline A. towneri & & DSM $14962^{\mathrm{T}}$ & Activated sludge \\
\hline A. ursingii & & NIPH $137^{\mathrm{T}}$ & Human specimens \\
\hline A. venetianus & & ATCC $31012^{\mathrm{T}}$ & Marine water \\
\hline \multirow[t]{2}{*}{ A. pittii ${ }^{\mathrm{a}}$} & 3 & ATCC 19004 & Human clinical specimens \\
\hline & 6 & ATCC 17979 & Human specimens \\
\hline \multirow[t]{9}{*}{ A. nosocomialis $^{\mathrm{a}}$} & $13 \mathrm{TU}$ & ATCC 17903 & Human clinical specimens \\
\hline & 13BJ, 14TU & ATCC 17905 & Human specimens \\
\hline & 14BJ & CCUG 14816 & Human specimens \\
\hline & $15 \mathrm{BJ}$ & SEIP 23.78 & Human specimens \\
\hline & $15 \mathrm{TU}$ & M 15la & Human specimens \\
\hline & 16 & ATCC 17988 & Human specimens \\
\hline & 17 & SEIP Ac87.314 & Human specimens, soil \\
\hline & Between 1 and 3 & 10095 & Human clinical specimens \\
\hline & Close to $13 \mathrm{TU}$ & 10090 & Human clinical specimens \\
\hline
\end{tabular}

in rainy months with a prevalence of $88 \%$ among patients which admitted to care centers [24-27]. On the other hand a number of various infections are related to this microorganism such as:

\section{Pneumonia}

The ventilator-associated pneumonia (VAP) is the most related infection with $A$. baumannii especially in intensive care units. Falagas and Lee studies performed the high percentage of death in this type of pneumonia [28, 29]. Albeit it's notable that alcohol consumption and tropical zone are predisposing fac- tors in VAP [18]. The first community-acquired pneumonia death was reported in Korea [30].

\section{Bacteremia}

A. baumannii bacteremia is respected as a third cause of mortality and morbidity in intensive care units [31].

\section{Trauma and Burn Infections}

A. baumannii is one of the main reasons of skin and soft tissue infections in burn wounds and trauma [32, 33]. Recognition between contamination and true infections 
and also the MDR strains existence have created a prominent challenge for infections treatment process [34].

However A. baumannii is also reported from meningitis, osteomyelitis, ICU-urinary tract infections, dental plaques, chronic and aggressive periodontitis and polymicrobial bacterial infections [35-37].

\section{PATHOGENICITY FACTORS}

The precise mechanism which involved in $A$. baumannii incidence is not clear so the predominant virulence factors are listed as below:

\section{Adhesion and Attachment}

Attachment of bacteria to epithelial cells is considered as one of the initial steps for colonization and infection in the host tissue. Epidemiological studies imply that Acinetobacter species can be colonized and survive on human skin and mucous membranes for days or weeks. Lee et al. described the adherence of A. baumannii to human bronchial epithelial cells in invitro [38]. The main cause of this phenomenon is correlated with bacteria adhesion molecules such as: OmpA, Omp33-36, Bap and cellular fibronectin [39].

\section{Motility}

There is a debate over the existence of $A$. baumannii motility. Recent studies demonstrated that $A$. baumannii is able to twitching because of the type IV pili. There is a positive correlation between the conserved sequences of pili subunits. Although there is no any empirical evidence on the existence of type IV pili in the twitching motility in A. baumannii, but in a study by Eijkelkamp, it was stated that this gene has been found in bacteria and the full sequence has been accessed [40]. The pili are under the control of signal transduction systems which include chemosensor complex (regulator and two-component system) [41]. As reported by Clemmer, twitching motility of the bacteria depends on the $T$ gene of pili. Disabling this gene will lead to a 54 percent reduction in movement in mutant strains. Furthermore, increasing the agar concentration may reduce the $A$. baumannii motility. Both free iron concentration and the cell population have an important role in $A$. baumannii motility [42]. It should be noted that ditching motility has been also observed in Acinetobacter anitratus [42, 43].

\section{Outer Membrane Proteins (OMP)}

Most of outer membrane proteins in Gram-negative bacteria are associated with antibiotic resistance, compatibility and pathogenicity in host cells. This factor plays a critical function in binding, bacterial invasion and prevents lysis by complement system activation. It has been associated with the apoptosis of epithelial cells through mitochondrial targeting [43]. This factor creates a resistance to the serum in Acinetobacter by binding to $\mathrm{H}$ factor [44]. A. baumannii can cause death of HEp-2 cells through cell death receptors or apoptosis of mitochondrial decay. The mechanism is related to apoptosis precursors [45].

\section{Outer Membrane Vesicles (OMV)}

OMVs are round-shaped nanovesicles that contain components of LPS, outer membrane proteins, lipids and nucleic acids [46]. Moreover, they involved in quorum sensing, virulence factors transferring, phagolysosome fusion inhibition, transferring genes and biofilm production [47]. Kwon studies show that these vesicles are produced during the growth phase [48]. The vesicles have antigenic properties, which can be used as vaccine targets. Previous studies suggested that vaccination with these particles leads to the rehabilitation of antibodies against multiple antigens of bacteria with bactericidal activity [49]. Jin et al. studies proved that the vesicles play an important role in transferring of outer membrane protein A to the host cells, which induce cytotoxicity after packaging the protein in the vesicles [46].

\section{$L P S$}

Bacterial LPS plays essential role in resistance to polymyxin antimicrobial peptides, complement activation, stimulate inflammation by stimulating TLR $-2^{2}$, TLR-2, TLR-4 and responses as well as synergistic interaction with exopolysaccharide capsule [50-52].

\section{Capsule}

There are many evidences for the existence of capsule in A. baumannii strains. For example, the strains which harbor the waal gene have ability to produce capsule formation [50]. Capsule has an important function in protecting bacteria against the host innate immune responses [53]. Russo et al. stated that K1 capsule of A. baumannii strains AB307-0294 is required to grow and survive in human serum in the peritoneal fluid. Likewise capsule is essential for survival in soft tissue infection in mice $[53,54]$. The tyrosine kinase of the inner membrane, $\mathrm{Wcz}$, is responsible for capsule accumulation and Wza causes the transferring of capsules from periplasmic space and outer membrane respectively. Also the role of $p t k$ and eps $A$ genes, in coding the related proteins have been identified [54].

\section{Biofilm Formation}

Acinetobacter has the ability in biofilm formation on biotic and abiotic surfaces [55]. Bacteria colonization, microcolony formation and exopolysaccharides secretion eventually lead to biofilm formation [56].

\footnotetext{
${ }^{2}$ Toll-like receptors.
} 
Biofilm also can affect the drug resistance and escapes from the host immune system. This process is controlled by Quorum sensing and two-component regulatory systems [57]. Pili, outer membrane proteins, extracellular polysaccharide and Bap are the most important factors in biofilm formation [39]. The Bap factor may lead to progress and sustainable development of biofilm through the maturation of biofilm formation on biotic and abiotic surfaces [57]. Espinal study illustrated that $A$. baumannii can produce biofilm in desiccated condition and protects the bacteria against the variation in wet circumstances [58]. Recent studies have pointed that the formation of biofilm is at least three times higher in the solid-liquid phase. Extracellular polysaccharide compounds $\left(\mathrm{PNAG}^{3}\right)$ is an essential factor for biofilm formation in $S$. aureus, $S$. epidermidis and A. baumannii which is encoded by pgaABCD locus cell-cell adhesions, protecting bacteria from innate immunity, biofilm stability in dynamic and stressful conditions have been affected by mentioned factor and considered as a vaccine candidate $[59,60]$.

\section{Pili and Secretion Systems}

Type I pili. Type I pili are respected as the most common structure of the outer surface protein in pathogenic bacteria. Eijkelkamp et al. identified four clusters of these genes in A. baumannii, which is called $c s u$-cluster. Proteomics studies verify that CsuD, CsuC and type I pili are effective in adherence [50].

Type IV pili. Cell surface-binding, twitching and biofilm formation are influenced by type IV pili. The numbers of Acinetobacter strains have pili encoded genes. The comP gene encoding the pilus-like protein which is homologous to pilA of type IV secretion system in Acinetobacter strains [61, 62].

Type V secretion system. The Ata auto-transporter secretion system in A. baumannii ATCC 17978 has an important role in pathogenicity, biofilm formation, binding to extracellular matrix proteins and attachment. Investigators identified that Ata is related to $58 \%$ of clinical isolates, while global strains do not harbor this gene [50].

Type VI secretion system. The Type VI secretion system (T6SSs) is recognized to be involved in cell invasion and competition amongst pathogens. It has been proposed for type 1 pili regulation and bacterial interaction. A number of studies have been reported the performance of this system in A. baumannii strains. It should be stated that $A$. nosocomialis strain M2 is using T6SS for destroying $E$. coli strains [50]. The T6SS gene cluster is controlled by resistance plasmid. This plasmid can be extremely conserved in $\mathrm{A}$. baumannii [63].

\footnotetext{
${ }^{3}$ Poly-N-acetylglucosamine.
}

\section{Enzymes}

Hydrolytic enzymes of Acinetobacter are consisting of phospholipases C and D [64]. These are lipolytic enzymes that catalyze the phospholipids releasing. These enzymes contribute to the pathogenesis of Gram-negative bacteria through the host cells lysis. Decomposition of the phospholipids in mucosal tissues will facilitate the bacterial invasion $[65,66]$.

Iron Uptake System: Pathogenic bacteria are using the iron acquisition systems for gaining the low level of free iron in the host. Binding to special receptors, transferring proteins and siderophores are the most prominent mechanisms for iron uptake [40]. Siderophores are high-affinity iron chelators which are produced by pathogenic bacteria and divided into three main categories based on iron chelating ligand, including catecholates, carboxylates and hydroxamates. Acinetobactin, a catechol- hydroxamate siderophore, is one of the iron acquisition systems that are broadly found in A. baumannii. Acinetobactin biosynthesis is encoded by bas $A-J$ genes and ABC super family. Acinetobactin complex is transmitted through protein receptors which are encoded by bau $A-F$ genes [67]. The number of acinetobactin producing strains utilizing the 30 and $15 \%$ of the saturated iron concentration in transferrin and lactoferrin as a sole source of iron. Inactivation of bauA and basD genes affects the ability of strains to the growth in iron limited condition. These results clarify that $A$. baumannii is able to survive in difficult conditions of iron deficiency, as well as emphasizing on the role of acinetobactin in bacterial infection and pathogenicity [68]. Feo system is another mechanism for providing iron, which is having cytosolic protein (FeoA), inner membrane protease (FeoB) and FeoC as repressor components [61].

\section{Blue-Light-Sensing Protein}

The Blue-light-sensing protein A (BlsA) can influence the A. baumannii pathogenicity. The BlsA protein expression is increased in the absence of light, however in the presence of blue light, the bacteria cannot produce biofilm [69].

\section{LABORATORY DIAGNOSIS}

Acinetobacter species are identified by Gram-negative, aerobic, non-fermentative, non-motile, catalase positive, indole negative and oxidase negative characteristics with gray-white mucoidal colonies with a diameter of 1.5 to $3 \mathrm{~mm}$. The species grow in standard microbiology media such as blood agar with 5\% sheep blood and trypticase soy agar [70]. The bacteria morphology is changing from coccobacilli to bacilli form in stationary phase and during rapid growth respectively [71]. To increase the number of Acinetobacter isolates from the environmental and clinical specimens, swab samples can be located in an enrichment medium with low $\mathrm{pH}$ containing acetate [72]. Some 
Table 2. Phenotypic characteristics of Acinetobacter species [85]

\begin{tabular}{|c|c|c|c|c|c|}
\hline \multirow{2}{*}{ Name of test } & \multicolumn{5}{|c|}{ Acinetobacter species } \\
\hline & $A c b$ complex & A. iwoffii & A. haemolyticus & A. junii & A. radioresistens \\
\hline Gram staining & \multicolumn{5}{|c|}{ Gram-negative cocci or coccobacilli } \\
\hline Catalase & + & + & + & + & + \\
\hline Oxidase & - & - & - & - & - \\
\hline Motility & - & - & - & - & - \\
\hline Urease & $\mathrm{V}$ & $\mathrm{V}$ & - & - & - \\
\hline Citrate & + & - & + & + & - \\
\hline OF glucose & + & - & $\mathrm{V}$ & - & - \\
\hline Nitrate reduction test & - & - & - & - & - \\
\hline Hemolysis & - & - & + & - & - \\
\hline Gelatin hydrolysis & - & - & + & - & - \\
\hline Growth at $42^{\circ} \mathrm{C}$ & + & - & - & - & - \\
\hline Chloramphenicol sensitivity & $\mathrm{R}$ & $\mathrm{S}$ & $\mathrm{R}$ & $\mathrm{R}$ & $\mathrm{R}$ \\
\hline Arginine hydrolysis & + & - & + & + & + \\
\hline
\end{tabular}

V: variable, S: sensitive, R: resistant, A. iwojfii: Acinetobacter iwoffii, Acb: Acinetobacter calcoaceticus-baumannii, A. haemolyticus: Acinetobacter hemolyticus, A. junii: Acinetobacter junii, A. radioresistens: Acinetobacter radioresistens, OF: oxidation-fermentation.

strains have sliding motility due to polar fimbriae. A few strains have the ability to grow at 41 to $44^{\circ} \mathrm{C}$, but some environmental species are not able to grow at temperatures above $30^{\circ} \mathrm{C}$. On the other hand, some strains are capable to produce acid through oxidation of D-glucose, D-ribose, D-xylose and L-arabinose. Both analytic systems, Vitek-2 and Microscan WalkAway, are used to identify the A. baumannii isolates, but not preferred for Acinetobacter baumannii complex $[73,74]$. For conforming the phenotypic methods (Biotyping, Phenotyping, Serotyping), molecular methods such as (ARDRA) ${ }^{4}$ [75], AFLP ${ }^{5}$ [76], Ribotyping [77], tRNA spacer fingerprinting [78], Restriction analysis of the 16S-23S RNA Intergenic Spacer Sequences [79], Sequence analysis of the $16 \mathrm{~S}-23 \mathrm{~S}$ rRNA gene spacer region [80], Sequencing of the rpoB [81], $\mathrm{MLST}^{6}, \mathrm{PFGE}^{7}$, repetitive extragenic palindromic sequence, 16s rDNA (ribosomal DNA) have been recognized [82], while ARDRA and AFLP techniques are reliable and well-established for Acinetobacter species classification [83, 84].

\section{Acinetobacter DRUG RESISTANCE AND TREATMENT}

The treatment of $A$. baumannii multidrug-resistant strains is one of the main challenges of health care units. Drug resistance strains were emerged accordance to genetic mobile elements essentially plasmids,

\footnotetext{
${ }^{4}$ ARDRA:Amplified Ribosomal DNA Restriction Analysis.

${ }_{6}^{5}$ AFLP: Amplified Fragment Length Polymorphism.

${ }^{6}$ Multilocus Sequence Typing.

${ }^{7}$ Pulsed-Field Gel Electrophoresis.
}

integrons and transposons. More than 30 types of IS elements (i.e., IS $A b a 1$ and IS $A b a 125$ ) have been found in Acinetobacter strains [86-88]. The bla $a_{O X A-23}$ gene in A. baumannii is transferred by Tn2006 and Tn2009 [89]. The $b l a_{O X A-58}$ gene is encoded by plasmid and provided by IS elements. It is noteworthy that $b l a_{P E R-1}$, $b l a_{P E R-7}$ and $b l a_{V E B-1}$ have been transmitted by these sequences [90]. Moreover Resistance Islands such as AbaRI have been identified in $A$. baumannii which have resistance genes for 45 different antibiotics and also heavy metals [87, 91].

It should be mentioned that this microorganism has an innate resistance to numerous antibiotics predominantly aminoglycosides, quinolones and broadspectrum of beta-lactams [92, 93].

\section{Beta-Lactam}

Resistance to this class of antibiotics is in effect of hydrolysis of antibiotics by beta-lactamase enzymes, changes in penicillin-binding proteins, modifying the structure and number of pore-forming proteins and activity of the efflux pumps [94].

\section{Enzymatic Mechanisms}

AmpC. AmpC enzyme encoded by both chromosomal and plasmid genes, belongs to class $\mathrm{C}$ beta-lactamase which is important in resistance to penicillins and extended-spectrum cephalosporins except cefepime and also carbapenems [95, 96].

Oxacilinase. Acinetobacter has class D of oxacilinase which has the innate ability to hydrolyze the clox- 
acillin and oxacillin. Five phylogenic subtypes of class $\mathrm{D}$ beta-lactamase have been identified in $A$. baumannii. This oxacilinase is belonging to bla $a_{O X A 5}$-like $\beta$-lactamase with penicillin and carbapenem hydrolyzing activity [97]. The $b l a_{O X A-51 / 69}$ and bla $_{O X A-24}$ are identified as the first gene cluster from carbapenem resistant strain in Spain. This class is consisting of bla $a_{O X A-25 / 26}$ and $b l a_{O X A-72}$. The third cluster is $b l a_{O X A-58}$ which has been found in Acinetobacter in Australia and Romania.

In general $\mathrm{CHDLs}^{8}$ is originated from carbapenem resistance plasmids [97, 98].

Metallo-beta-lactamase. Carbapenems are recognized as one of the most effectual antimicrobial agents for treatment of $A$. baumannii multi-drug resistant strains, while nowadays resistance to these antibiotics has been increased. Alternatively, these strains were resistance to all classes of antibiotics except colistin and tigecycline, however resistant to these drugs has been also reported [99]. One of the most common mechanisms of resistance to carbapenems is producing oxacilinase which is related to $b a_{O X A-23}, b a_{O X A-40}$ and bla ${ }_{O X A-58}[97,98]$. Class B (Metallo- $\beta$-lactamase) strains consisting of VIM, IMP, and SIM have been reported in $A$. baumannii, especially in the regions of Asia-Pacific and Latin America. These genes result in resistance to all carbapenems except aztreonam which is associated with class 1 integron [97, 100]. Recently, New Delhi metallo-beta-lactamase (NDM) has been found in clinical $A$. baumannii. At the present, NDM-1 and NDM-2 are acknowledged as one of the causes of CRAB (Carbapenem-resistant Acinetobacter baumannii) in Europe, China, Japan and Egypt [101, 102]. Klebsiella pneumoniae carbapenemase $(K P C)$-producing bacteria are related as $A$. baumannii carbapenem resistant strains, for instance type 2, 3 and 4 of bla $_{K P C}$ genes were reported in Puerto Rico [103]. The novel narrowspectrum beta-lactamase SCO-1, TEM-1, CARB-2, CARB-4, CARB-8, bla $a_{O X A-20}, b l a_{O X A-21}$ and $b l a_{O X A-37}$ have been recognized in $A$. baumannii. The presence of PER-1-type ESBLs has been observed for the first time in European countries [97, 104]. The bla $a_{P E R-7}$ gene that was isolated from patient in Paris, in comparison to type-1 has the more hydrolytic enzyme activity against aztreonam and cephalosporins [105107]. The bla $a_{P E R}$ and $b l a_{V E B}$ beta-lactamase genes have been found as a second class of beta-lactamases in Enterobacteriaceae and also in A. baumannii and associated with hospital outbreak strains. It should be noted that the $b l a_{C T X-M}$ variants, especially $b l a_{C T X-M 15}$ has a low prevalence in A. baumannii [107-109].

\section{Non Enzymatic Mechanisms}

Membrane permeability. Membrane permeability may cause one of the reasons of Gram-negative bacteria resistance mechanism, in which Limanesky and

\footnotetext{
${ }^{8}$ Carbapenem-Hydrolysing Class D Beta-Lactamases.
}

colleagues demonstrated that the lack of 29-kDa outer membrane protein has a considerable role in resistance to carbapenems [109]. Proteomics studies showed that special outer membrane proteins (HMP-AB) may cause resistance to beta-lactam antimicrobial agents $[110,111]$. Resistance to beta-lactams can be occurring amongst the efflux systems, resistance-nodulation-cell division $(R N D)$ pumps and related components such as AdeABC [112, 113]. Roca and colleagues illustrated that AdeABC efflux system is involved in pumping out the monobactams and third-generation of cephalosporins [114]. On the other hand the lack of membrane pores as 33-kDa protein, 29-kDa protein (carO) and 49-kDa protein which are homologous to OprD have a pivotal function in antimicrobial resistance mechanisms [115].

Penicillin-binding proteins (PBPs). Exchanging the affinity or the protein expression can prompt antimicrobial resistance profiles. In some strains, resistant to carbapenems is correlated with an increasing in the expression level of these proteins with low affinity.

Aminoglycosides. Resistance to aminoglycosides in the $A$. baumannii is involved by aminoglycosides modifying enzymes which are present in bacterial chromosome, plasmids, integrons or Acinetobacter Resistance Island with the aim of altering the hydroxyl and amino groups like acetyl-transferase, nucleotidyltransferase and phosphotransferase [116, 117]. The arm $A$ gene (aminoglycoside resistance methyltransferase) that may found in combination with the $b a_{O X A-23}$, is contributing to resistance to all types of aminoglycosides [118].

Quinolones. Resistance to quinolones is related to a point mutation in quinolone-resistance determining region (QRDR) in DNA gyrase and type-V topoisomerase. The mutation in gyrase $A$ and $\operatorname{par} C$ genes can cause the rearrangement of Ser83 to Leu in gyrase A and Ser80 to Leu in parC in A. baumannii [119-121].

Polymyxin. The majority of $A$. baumannii strains are susceptible to polymyxin. This antibiotic alters bacterial outer membrane permeability and disrupts the cytoplasmic membrane. The colistin resistant strains are producing outer membrane proteins which comprise outer membrane proteins, chaperones, protein biosynthetic factors and metabolic enzymes [122]. Mutation and increasing expression of $p m r A / p m r B$ genes have an effective role in resistance to colistin. Resistance can occur through the loss of the ability to produce the lipopolysaccharide components by mutation in $\operatorname{lp} x A, B$, and $C$ genes $[123,124]$.

Efflux system. Bacteria can extrude the antimicrobial agents out of the cell via pumps. These pumps are divided into five categories based on the similarity of amino acid sequences, an energy sources, number of components and type of substrates.

(1) ATP-Binding Cassette (ABC);

(2) Multidrug and Toxic Compound Extrusion (MATE); 
(3) Small Multidrug Resistance (SMR);

(4) Major Facilitator Superfamily (MFS);

(5) Resistance-Nodulation-Division (RND) [125].

The first known RND in A. baumannii is AdeABC, in which type $B$ has been accepted as multidrug transporter protein, but type $\mathrm{A}$ and $\mathrm{C}$ are outer membrane and periplasmic proteins [126]. This system is under the control of Ade SR Two-component system that expresses this pump to reduce the susceptibility to antibiotics similar to gentamicin, kanamycin, tobramycin, netilmicin, amikacin, erythromycin, tetracycline, trimethoprim, chloramphenicol, ofloxacin, pefloxacin, norfloxacin and tigecycline [127, 128]. AdeABC efflux pump-encoding genes with class 1 integron have been seen in Acinetobacter strains [129]. With disabling adeIJK efflux pump through the allelic displacement, the resistance to AdeABC pump has been decreased [129, 130]. The third type of RND pump is AdeFGH that responsible for resistance to clindamycin, fluoroquinolone, chloramphenicol, trimethoprim, and also in reducing the susceptibility to tetracycline, tigecycline and sulfonamides [111]. The CraA efflux pump of MFS family is regarded in chloramphenicol resistance $A$. baumannii strains or intrinsic resistance to other antibiotics [131]. The AmvA family is another pump which is responsible for erythromycin excretion [132]. Tet efflux pump can be transported by mobile genetic elements (transposon, plasmid or resistance Islands). This type is consisting of two parts $\mathrm{A}$ and $\mathrm{B}$ which contributed in resistance to tetracycline and tetracycline/minocycline respectively [133]. The AbeM is the only member of the MATE family with significant role in pumping out the aminoglycoside, fluoroquinolone, chloramphenicol, trimethoprim and ethidium bromide [134]. Also SMR family (Abe $\mathrm{S}$ ) is known in resistance to chloramphenicol, novobiocin and erythromycin [135].

\section{Treatment}

The following antimicrobial agents are used to treat Acinetobacter various infections:

Carbapenems. Carbapenems are still remaining choice as antimicrobial agents for Acinetobacter susceptible isolates. The imipenem is the most potent agent in comparison to meropenem, for treatment of multidrug-resistant strains [1]. Unfortunately, carbapenem-resistant Acinetobacter isolates are increasingly reported worldwide.

Beta-Lactamase inhibitors. Beta-Lactamase inhibitors (sulbactam) have intrinsic activity against many Acinetobacter strains. The presence of beta-lactam antibiotics (e.g., Ampicillin) in combination with the beta-lactamase inhibitor does not contribute activity or synergy $[104,136]$. Monotherapy with sulbactam is not recommended for severe Acinetobacter infections. Levin et al. reported a cure rate of $67 \%$ using ampicil- lin-sulbactam to treat carbapenem-resistant Acinetobacter infections [137].

Tigecycline. Tigecycline, a relatively new glycylcycline agent has bacteriostatic activity against multidrug-resistant Acinetobacter species [3].

Aminoglycosides. Aminoglycoside agents (tobramycin and amikacin) are therapeutic options for multidrug-resistant Acinetobacter isolates. These agents are usually used in combination with other antimicrobial agents.

Polymyxin. Due to limited therapeutic options, clinicians have returned to the use of polymyxin $\mathrm{B}$ or polymyxin E (Colistin) for the most MDR strains [4].

Future Therapeutic Considerations. Using highly charged copper-based biocides, bacteriophage treatment, passive or active immunization, modification of bacterial virulence factors, by inhibition of quorum sensing and bacterial secretion systems are the novel therapeutic strategies against Acinetobacter infections [5].

\section{ACKNOWLEDGMENTS}

We thank Amirhossein Ebrahimzadeh Namvar for all supports.

\section{COMPLIANCE WITH ETHICAL STANDARDS}

The authors declare that they have no conflict of interest. This article does not contain any studies involving animals or human participants performed by any of the authors.

\section{REFERENCES}

1. Eveillard, M., Kempf, M., Belmonte, O., Pailhories, H., and Joly-Guillou, M.L., Reservoirs of Acinetobacter baumannii outside the hospital and potential involvement in emerging human community-acquired infections, Int. J. Infect. Dis., 2013, vol. 17, no. 10, pp. 802805.

2. Brisou, J. and Prevot, A.R., Studies on bacterial taxonomy. X. The revision of species under Achromobacter group, Ann. Inst. Pasteur (Paris), 1954, vol. 86, no. 6, 722-728.

3. Baumann, P., Doudoroff, M., and Stanier, R.Y., A study of the Moraxella group II oxidative-negative species (genus Acinetobacter), J. Bacteriol., 1968, vol. 95, no. 5, pp. 1520-1541.

4. Bouvet PJM, Grimont PAD. Taxonomy of the genus Acinetobacter with the recognition of Acinetobacter baumannii sp. nov., Acinetobacter haemolyticus sp. nov., Acinetobacter johnsonii sp. nov., and Acinetobacter junii sp. nov., and emended descriptions of Acinetobacter calcoaceticus and Acinetobacter lwofii, Int. J. Syst. Bacteriol., 1986, vol. 36, pp. 228-240.

5. Gerner-Smidt, P., Ribotyping of the Acinetobacter calcoaceticus-Acinetobacter baumannii complex, J. Clin. Microbiol., 1992, vol. 30, no. 10, pp. 2680-2685.

6. Nemec, A., De Baere, T., Tjernberg, I., Vaneechoutte, M., van der Reijden, T.J., and Dijkshoorn, L., 
Acinetobacter ursingii sp. nov. and Acinetobacter schindleri sp. nov., isolated from human clinical specimens, Int. J. Syst. Evol. Microbiol., 2001, vol. 51, pp. 18911899.

7. Nemec, A., Dijkshoorn, L., Cleenwerck, I, De Baere, T., Janssens, D., Van Der Reijden, T.J., Jezek, P., and Vaneechoutte, M., Acinetobacter parvus sp. nov., a small-colony-forming species isolated from human clinical specimens, Int. J. Syst. Evol. Microbiol., 2003, vol. 53, pp. 1563-1567.

8. Carr, E.L., Kampfer, P., Patel, B.K., Gürtler, V., and Seviour, R.J., Seven novel species of Acinetobacter isolated from activated sludge, Int. J. Syst. Evol. Microbiol., 2003, vol. 53, part 4, pp. 953-963.

9. Nemec, A., Krizova, L., Maixnerova, M., van der Reijden, T.J., Deschaght, P., Passet, V., Vaneechoutte, M., Brisse, S., and Dijkshoorn, L., Genotypic and phenotypic characterization of the Acinetobacter calcoaceticusAcinetobacter baumannii complex with the proposal of Acinetobacter pittii sp. nov. (formerly Acinetobacter genomic species 3 ) and Acinetobacter nosocomialis sp. nov. (formerly Acinetobacter genomic species 13TU), Res. Microbiol., 2011, vol. 162, pp. 393-404.

10. Fournier, P.E. and Richet, H., The epidemiology and control of Acinetobacter baumannii in health care facilities, Clin. Infect. Dis., 2006, vol. 42, no. 5, pp. 692699.

11. Necati Hakyemez, I., Kucukbayrak, A., Tas, T., Burcu Yikilgan, A., Akkaya, A., Yasayacak, A., and Akdeniz, H., Nosocomial Acinetobacter baumannii, Pak. J. Med. Sci., 2013, vol. 29, no. 5, pp. 1245-1248.

12. Berlau, J., Aucken, H., Malnick, H., and Pitt, T., Distribution of Acinetobacter species on skin of healthy humans, Eur. J. Clin. Microbiol. Infect. Dis., 1999, vol. 18, no. 3, pp. 179-183.

13. Figueiredo, S., Bonnin, R.A., Poirel, L., Duranteau, J., and Nordmann, P., Identification of the naturally occurring genes encoding carbapenem-hydrolysing oxacillinases from Acinetobacter haemolyticus, Acinetobacter johnsonii, and Acinetobacter calcoaceticus, Clin. Microbiol. Infect., 2012, vol. 18, no. 9, pp. 907-913.

14. Allen, K.D. and Green, H.T., Hospital outbreak of multi-resistant Acinetobacter anitratus: An airborne mode of spread, J. Hosp. Infect., 1987, vol. 9, no. 2, pp. 110-119.

15. Munoz-Price, L.S., Fajardo-Aquino, Y., Arheart, K.L., Cleary, T., DePascale, D., Pizano, L., Namias, N., Rivera, J.I., O'Hara, J.A., and Doi, Y., Aerosolization of Acinetobacter baumannii in a trauma ICU, Crit. Care Med., 2013, vol. 41, pp. 1915-1918.

16. Gootz, T.D. and Marra, A., Acinetobacter baumannii: An emerging multidrug-resistant threat, Expert Rev. Anti-Infect. Ther., 2008, vol. 6, no. 3, pp. 309-325.

17. Maragakis, L. and Perl, T., Acinetobacter baumannii: Epidemiology, antimicrobial resistance and treatment options, Clin. Infect. Dis., 2008, vol. 46, pp. 12541263.

18. Eber, M.R., Shardell, M., Schweizer, M.L., Laxminarayan, R., and Perencevich, E.N., Seasonal and temperature-associated increases in gram-negative bacte- rial bloodstream infections among hospitalized patients, PLoS One, 2011, vol. 6, no. 9, p. e25298.

19. Chung, D.R., Song, J., Kim, S.H., Thamlikitkul, V., Huang, S.G., Wang, H., So, T.M., Yasin, R.M., Hsuh, P.R., Carlos, C.C., Hsu, L.Y., Buntaran, L., Lalitha, M.K., Kim, M.J., Choi, J.Y., Kim, S.I., Ko, K.S., Kang, C.I., and Peck, K.R., Asian network for surveillance of resistant pathogens study group. high prevalence of multidrug-resistant non fermenters in hospital-acquired pneumonia in Asia, Am. J. Respir. Crit. Care Med., 2011, vol. 184, no. 12, pp. 1409-1417.

20. Chaudhary, M. and Payasi, A., Incidence, prevalence and control of multidrug resistant (MDR) carbapenemase producing Acinetobacter baumanii in Indian intensive care units, J. Pharm. Res., 2013, vol. 7, no. 2, pp. $175-180$.

21. Ali, A., Botha, J., and Tiruvoipati, R., Fatal skin and soft tissue infection of multidrug resistant: A case report, Int. J. Surg. Case Rep., 2014, vol. 5, no. 8, pp. 532-536.

22. Custovic, A., Smajlovic, J., Tihic, N., Hadzic, S., Ahmetagic, S., and Hadzagic, H., Epidemiological monitoring of nosocomial infections caused by Acinetobacter baumannii, Med. Arh., 2014, vol. 68, no. 6, pp. 402-406.

23. Cristina, M.L., Spagnolo, A.M., Cenderello, N., Fabbri, P., Sartini, M., Ottria, G., and Orlando, P., Multidrug-resistant Acinetobacter baumannii outbreak: An investigation of the possible routes of transmission, Publ. Health, 2013, vol. 127, no. 4, pp. 386-391.

24. Ong, C.W., Lye, D.C., Khoo, K.L., Chua, G.S., Yeoh, S.F., Leo, Y.S., Tambyah, P.A., and Chua, A.C., Severe community-acquired Acinetobacter baumannii pneumonia: An emerging highly lethal infectious disease in the Asia-Pacific, Respirology, 2009, vol. 14, pp. 1200-1205.

25. Leung, W.S., Chu, C.M., Tsang, K.Y., Lo, F.H., Lo, K.F., and Ho, P.L., Fulminant community-acquired Acinetobacter baumannii pneumonia as a distinct clinical syndrome, Chest J., 2006, vol. 129, pp. 102-109.

26. Wang, J.T., McDonald, L.C., Chang, S.C., and Ho, M., Community-acquired Acinetobacter baumannii bacteremia in adult patients in Taiwan, J. Clin. Microbiol., 2002, vol. 40, pp. 1526-1529.

27. Davis, J.S., McMillan, M., Swaminathan, A., Kelly, J.A., Piera, K.E., Baird, R.W., Currie, B.J., and Anstey, N.M., A 16-year prospective study of community-onset bacteremic Acinetobacter pneumonia: Low mortality with appropriate initial empirical antibiotic protocols, Chest, 2014, vol. 146, no. 4, pp. 1038-1045.

28. Falagas, M.E. and Rafailidis, P.I., Attributable mortality of Acinetobacter baumannii: No longer a controversial issue, Crit. Care, 2007, vol. 11, no. 3, p. 134.

29. Lee, N.Y., Lee, H.C., Ko, N.Y., Chang, C.M., Shih, H.I., Wu, C.J., and Ko, W.C., Clinical and economic impact of multidrug resistance in nosocomial Acinetobacter baumannii bacteremia, Infect. Control Hosp. Epidemiol., 2007, vol. 28, pp. 713-719.

30. Oh, Y.J., Song, S.H., Baik, S.H., Lee, H.H., Han, I.M., and Oh, D.H., A case of fulminant community-ac- 
quired Acinetobacter baumannii pneumonia in Korea, Korean J. Intern. Med., 2013, vol. 28, pp. 486-490.

31. Oliveira, V.D., Rubio, F.G., Almeida, M.T., Nogueira, M.C., and Pignatari, A.C., Trends of 9,416 multidrug-resistant Gram-negative bacteria, Rev. Assoc. Med. Bras., 2015, vol. 61, pp. 244-249.

32. Albrecht, M.C., Griffith, M.E., Murray, C.K., Chung, K.K., Horvath, E.E., Ward, J.A., Hospenthal, D.R., Holcomb, J.B., and Wolf, S.E., Impact of Acinetobacter infection on the mortality of burn patients, J. Am. Coll. Surg., 2006, vol. 203, no. 4, pp. $546-550$.

33. Sebeny, P.J., Riddle, M.S., and Petersen, K., Acinetobacter baumannii skin and soft-tissue infection associated with war trauma, Clin. Infect. Dis., 2008, vol. 47, pp. 444-449.

34. Keen, E.F., Robinson, B.J., Hospenthal, D.R., Aldous, W.K., Wolf, S.E., Chung, K.K., and Murray, C.K., Prevalence of multidrug-resistant organisms recovered at a military burn center, Burns, 2010, vol. 36, pp. 819-825.

35. Kourbeti, I.S., Vakis, A.F., Ziakas, P., Karabetsos, D., Potolidis, E., Christou, S., and Samonis, G., Infections in patients undergoing craniotomy: Risk factors associated with post-craniotomy meningitis, J. Neurosurg., 2015, vol. 122, pp. 1113-1119.

36. Davis, K.A., Moran, K.A., McAllister, C.K., and Gray, P.J., Multidrug-resistant Acinetobacter extremity infections in soldiers, Emerging Infect. Dis., 2005, vol. 11, no. 8, pp. 1218-1224.

37. Johnson, E.N., Burns, T.C., Hayda, R.A., Hospenthal, D.R., and Murray, C.K., Infectious complications of open type III tibia fractures among combat casualties, Clin. Infect. Dis., 2007, vol. 4, no. 4, pp. 409415.

38. Lee, J.C., Koerten, H., van den Broek, P., Beekhuizen, H., Wolterbeek, R., van den Barselaar, M., van der Reijden, T., van der Meer, J., van de Gevel, J., and Dijkshoorn, L., Adherence of Acinetobacter baumannii strains to human bronchial epithelial cells, Res. Microbiol., 2006, vol. 157, pp. 360-366.

39. Doi, Y., Murray, G.L., and Peleg, A.Y., Acinetobacter baumannii: Evolution of antimicrobial resistancetreatment options, Semin. Respir. Crit. Care Med., 2015, vol. 36, no. 1, pp. 85-98.

40. Eijkelkamp, B.A., Hassan, K.A., Paulsen, I.T., and Brown, M.H., Investigation of the human pathogen Acinetobacter baumannii under iron limiting conditions, BMC Genomics, 2011, vol. 12, p. 126.

41. Mattick, J.S., Type IV pili and twitching motility, Annu. Rev. Microbiol., 2002, vol. 56, pp. 289-314.

42. Clemmer, K.M., Bonomo, R.A., and Rather, P.N., Genetic analysis of surface motility in Acinetobacter baumannii, Microbiology, 2011, vol. 157, part 9, pp. 2534-2544.

43. Lee, J.S., Choi, C.H., Kim, J.W., and Lee, J.C., Acinetobacter baumannii outer membrane protein a induces dendritic cell death through mitochondrial targeting, J. Microbiol., 2010, vol. 48, pp. 387-392.
44. Smani, Y., Fàbrega, A., Roca, I., Sánchez-Encinales, V., Vila, J., and Pachón, J., Role of OmpA in the MDRphenotype of Acinetobacter baumannii, Antimicrob. Agents Chemother., 2014, vol. 58, pp. 1806-1808.

45. Choi, C.H., Lee, E.Y., Lee, Y.C., Park, T.I., Kim, H.J., Hyun, S.H., Kim, S.A., Lee, S.K., and Lee, J.C., Outer membrane protein 38 of Acinetobacter baumannii localizes to the mitochondria and induces apoptosis of epithelial cells, Cell. Microbiol., 2005, vol. 7, no. 8, pp. 1127-1138.

46. Jin, J.S., Kwon, S.O., Moon, D.C., Gurung, M., Lee, J.H., Kim, S.I., and Lee, J.C., Acinetobacter baumannii secretes cytotoxic outer membrane protein a via outer membrane vesicles, PLoS One, 2011, vol. 28, no. 2, p. e17027.

47. McConnell, M.J., Rumbo, C., Bou, G., and Pachón, J., Outer membrane vesicles as an acellular vaccine against Acinetobacter baumannii, Vaccine, 2011, vol. 29, pp. 5705-5710.

48. Kwon, S.O., Gho, Y.S., Lee, J.C., and Kim, S.I., Proteome analysis of outer membrane vesicles from a clinical Acinetobacter baumannii isolate, FEMS Microbiol. Lett., 2009, vol. 297, pp. 150-156.

49. Schild, S., Nelson, E.J., and Camilli, A., Immunization with Vibrio cholera outer membrane vesicles induces protective immunity in mice, Infect. Immun., 2008, vol. 76, pp. 4554-4563

50. Eijkelkamp, B.A., Stroeher, U.H., Hassan, K.A., Paulsen, I.T., and Brown, M.H., Comparative analysis of surface-exposed virulence factors of Acinetobacter baumannii, BMC Genomics, 2014, vol. 15, p. 1020.

51. Goel, V.K. and Kapil, A., Monoclonal antibodies against the iron regulated outer membrane proteins of Acinetobacter baumannii are bactericidal, BMC Microbiol., 2001, vol. 1, pp. 16-24.

52. Erridge, C., Moncayo-Nieto, O.L., Morgan, R., Young, M., and Poxton, I.R., Acinetobacter baumannii lipopolysaccharides are potent stimulators of human monocyte activation via Toll-like receptor 4 signaling, J. Med. Microbiol., 2007, vol. 56, part 2, pp. 165-171.

53. Russo, T.A., Beanan, J.M., Olson, R., MacDonald, U., Luke, N.R., Gill, S.R., and Campagnari, A.A., Rat pneumonia and soft tissue infection models for the study of Acinetobacter baumannii biology, Infect. Immun., 2008, vol. 76, pp. 3577-3586.

54. Russo, T.A., Luke, N.R., Beanan, J.M., Olson, R., Sauberan, S.L., MacDonald, U., Schultz, L.W., Umland, T.C., and Campagnari, A.A., The K1 capsular polysaccharide of Acinetobacter baumannii strain 307-0294 is a major virulence factor, Infect. Immun., 2010, vol. 78, pp. 3993-4000.

55. Cevahir, N., Demir, M., Kaleli, I., Gurbuz, M., and Tikvesli, S., Evaluation of biofilm production, gelatinase activity, and mannose-resistant hemagglutination in Acinetobacter baumannii strains, J. Microbiol. Immunol. Infect., 2008, vol. 41, no. 6, pp. 513-518.

56. Vallenet, D., Nordmann, P., rieBarbe, V., Poirel, L., Mangenot, S., Bataille, E., Dossat, C., Gas, S., Kreimeyer, A., Lenoble, P., Oztas, S., Poulain, J., Segurens, B., Robert, C., Abergel, C., and Claverie, J.M., 
Comparative analysis of Acinetobacters: Three genomes for three lifestyles, PLoS One, 2008, vol. 19, no. 3 , p. e 1805 .

57. Gaddy, J.A. and Actis, L.A., Regulation of Acinetobacter baumannii biofilm formation, Future Microbiol., 2009, vol. 4, no. 3, pp. 273-238.

58. Espinal, P., Martı, S., and Vila, J., Effect of biofilm formation on the survival of Acinetobacter baumannii on dry surfaces, J. Hosp. Infect., 2012, vol. 80, no. 1, pp. 56-60.

59. Kropec, A., Maira-Litran, T., Jefferson, K.K., Grout, M., Cramton, S.E., Götz, F., Goldmann, D.A., and Pier, G.B., Poly N-acetylglucosamine production in Staphylococcus aureus is essential for virulence in murine models of systemic infection, Infect. Immun., 2005, vol. 73, pp. 6868-6876.

60. Choi, A.H., Slamti, L., Avci, F.Y., Pier, G.B., and Maira-Litrán, T., The pgaABCD locus of Acinetobacter baumannii encodes the production of poly- $\beta$ 1-6-N-acetylglucosamine, which is critical for biofilm formation, J. Bacteriol., 2009, vol. 191, no. 19, pp. 5953-63.

61. Antunes, L.C., Imperi, F., Carattoli, A., and Visca, P., Deciphering the multifactorial nature of Acinetobacter baumannii pathogenicity, PLoS One, 2011, vol. 6, no. 8, p. e22674.

62. Metzgar, D., Bacher, J.M., Pezo, V., Reader, J., Döring, V., Schimmel, P., Marlière, P., and de CrécyLagard, V., Acinetobacter sp. ADP1: An ideal model organism for genetic analysis and genome engineering, Nucleic Acids Res., 2004, vol. 32, pp. 5780-5790.

63. Weber, B.S., Ly, P.M., Irwin, J.N., Pukatzki, S., and Feldman, M.F., A multidrug resistance plasmid contains the molecular switch for type VI secretion in Acinetobacter baumannii, Proc. Natl. Acad. Sci. U. S. A., 2015, vol. 112, pp. 9442-9447.

64. Hosseingholi, E.Z., Rasooli, I., and Gargari, S.L., In silico analysis of Acinetobacter baumannii phospholipase D as a subunit vaccine candidate, Acta Biotheor., 2014, vol. 62, no. 4, pp. 455-478.

65. Jacobs, A.C., Hood, I., Boyd, K.L., Olson, P.D., Morrison, J.M., Carson, S., Sayood, K., Iwen, P.C., Skaar, E.P., and Dunman, P.M., Inactivation of phospholipase D diminishes Acinetobacter baumannii pathogenesis, Infect. Immun., 2010, vol. 78, no. 5, pp. 1952-1962.

66. Stahl, J., Bergmann, H., Göttig, S., Ebersberger, I., and Averhoff, B., Acinetobacter baumannii virulence is mediated by the concerted action of three phospholipases D, PLos One, 2015, vol. 10, no. 9, p. e0138360.

67. Hasan, T., Choi, C., and Oh, M., Genes involved in the biosynthesis and transport of acinetobactin in Acinetobacter baumannii, Genomics Inform., 2015, vol. 13, no. 1, pp. 2-6.

68. Zimbler, D.L., Penwell, F., Gaddy, J.A., Menke, S.M., Tomaras, A.P., Connerly, P.L., and Actis, L.A., Iron acquisition functions expressed by the human pathogen Acinetobacter baumannii, Biometals, 2009, vol. 22, pp. 23-32.
69. Richards, A.M., Abu Kwaik, Y., and Lamont, R.J., Code blue: Acinetobacter baumannii, a nosocomial pathogen with a role in the oral cavity, Mol. Oral Microbiol., 2015, vol. 30, pp. 2-15.

70. Antunes, L.C., Visca, P., and Towner, K.J., Acinetobacter baumannii: Evolution of a global pathogen, Pathog. Dis., 2014, vol. 71, no. 3, pp. 292-230.

71. Young, L.S., Sabel, A.L., and Price, C.S., Epidemiologic, clinical, and economic evaluation of an outbreak of clonal multidrug-resistant Acinetobacter baumannii infection in a surgical intensive care unit, Infect. Control Hosp. Epidemiol., 2007, vol. 28, pp. 1247-1254.

72. Baumann, P., Isolation of Acinetobacter from soil and water, J. Bacteriol., 1968, vol. 96, no. 1, pp. 39-42.

73. Kulah, C., Aktas, E., Comert, F., Ozlu, N., Akyar, I., and Ankarali, H., Detecting imipenem resistance in Acinetobacter baumannii by automated systems (BD Phoenix, Microscan WalkAway, Vitek 2); high error rates with Microscan WalkAway, BMC Infect. Dis., 2009, vol. 9, pp. 16-30.

74. O'Hara, C.M. and Miller, J.M., Ability of the MicroScan rapid Gram-negative ID type 3 panel to identify nonenteric glucose-fermenting and nonfermenting Gramnegative bacilli, J. Clin. Microbiol., 2002, vol. 40, pp. 3750-3752.

75. Dijkshoorn, L., Van Harsselaar, B., Tjernberg, I., Bouvet, P.J., and Vaneechoutte, M., Evaluation of amplified ribosomal DNA restriction analysis for identification of Acinetobacter genomic species, Syst. Appl. Microbiol., 1998, vol. 21, no. 1, pp. 33-39.

76. Janssen, P., Maquelin, K., Coopman, R., Tjernberg, I., Bouvet, P., Kersters, K., and Dijkshoorn, L., Discrimination of Acinetobacter genomic species by AFLP fingerprinting, Int. J. Syst. Bacteriol., 1997, vol. 47, no. 4, pp. 1179-1187.

77. Chen, T.L., Siu, L.K., Wu, R.C., Shaio, M.F., Huang, L.Y., Fung, C.P., Lee, C.M., and Cho, W.L., Comparison of one tube multiplex PCR, automated ribotyping and intergenic spacer (ITS) sequencing for rapid identification of Acinetobacter baumannii, Clin. Microbiol. Infect., 2007, vol. 13, no. 8, pp. 801-806.

78. Ehrenstein, B., Bernards, A.T., Dijkshoorn, L., Gerner-Smidt, P., Towner, K.J., Bouvet, P.J., Daschner, F.D., and Grundmann, H., Acinetobacter species identification by using tRNA spacer fingerprinting, J. Clin. Microbiol., 1996, vol. 34, no. 10, pp. 2414-2420.

79. Dolzani, L., Tonin, E., Lagatolla, C., Prandin, L., and Monti-Bragadin, C., Identification of Acinetobacter isolates in the $A$. calcoaceticus $-A$. baumannii complex by restriction analysis of the $16 \mathrm{~S}-23 \mathrm{~S}$ rRNA intergenic spacer sequences, J. Clin. Microbiol., 1995, vol. 33, no. 5, pp. 1108-1813.

80. Chang, H.C., Wei, Y.F., Dijkshoorn, L., Vaneechoutte, M., Tang, C.T., and Chang, T.C., Species-level identification of isolates of the Acinetobacter calcoaceticus-Acinetobacter baumannii complex by sequence analysis of the $16 \mathrm{~S}-23 \mathrm{~S}$ rRNA gene spacer region, J. Clin. Microbiol., 2005, vol. 43, no. 4, pp. 16321639. 
81. La Scola, B., Gundi, V.A., Khamis, A., and Raoult, D., Sequencing of the $r p o B$ gene and flanking spacers for molecular identification of Acinetobacter species, J. Clin. Microbiol., 2006, vol. 44, pp. 827-832.

82. Gallagher, L., Ramage, E., Weiss, E., Radey, M., Hayden, H., Held, K., Huse, H., Zurawski, D., Brittnacher, M., and Manoil, C., Resources for genetic and genomic analysis of emerging pathogen Acinetobacter baumannii, J. Bacteriol., 2015, vol. 197, pp. 2027-2035.

83. Tiwari, V. and Tiwari, M., Quantitative proteomics to study carbapenem resistance in Acinetobacter baumannii, Front. Microbiol., 2014, vol. 26, p. 512.

84. Long, Q., Huang, C., Liao, P., and Xie, J., Proteomic insights into Acinetobacter baumannii drug resistance and pathogenesis, Crit. Rev. Eukaryotic Gene Expression, 2013, vol. 23, pp. 227-255.

85. Gupta, N., Gandham, N., Jadhav, S., and Mishra, R.N., Isolation and identification of Acinetobacter species with special reference to antibiotic resistance, J. Nat. Sci. Biol. Med., 2015, vol. 6, no. 1, pp. 159-62.

86. Siguier, P., Perochon, J., Lestrade, L., Mahillon, J., and Chandler, M., IS finder: The reference centre for bacterial insertion sequences, Nucleic Acids Res., 2006, vol. 34, pp. D32-D36.

87. Adams, M.D., Chan, E.R., Molyneaux, N.D., and Bonomo, R.A., Genome wide analysis of divergence of antibiotic resistance determinants in closely related isolates of Acinetobacter baumannii, Antimicrob. Agents Chemother., 2010, vol. 54, no. 9, pp. 3569-3577.

88. Adams-Haduch, J.M., Onuoha, E.O., Bogdanovich, T., Tian, G.B., Marschall, J., Urban, C.M., Spellberg, B.J., Rhee, D., Halstead, D.C., Pasculle, A.W., and Doi, Y., Molecular epidemiology of carbapenem-nonsusceptible Acinetobacter baumannii in the United States, J. Clin. Microbiol., 2011, vol. 49, no. 11, pp. 3849-3854.

89. Adams, M.D., Goglin, K., Molyneaux, N., Hujer, K.M., Lavender, H., Jamison, J.J., MacDonald, I.J., Martin, K.M., Russo, T., Campagnari, A.A., Hujer, A.M., Bonomo, R.A., and Gill, S.R., Comparative genome sequence analysis of multidrug-resistant Acinetobacter baumannii, J. Bacteriol., 2008, vol. 190, no. 24, pp. 8053-8064.

90. Evans, B.A., Hamouda, A., Towner, K.J., and Amyes, S.G.B., Novel genetic context of multiple blaOXA-58 genes in Acinetobacter genospecies 3, J. Antimicrob. Chemother., 2010, vol. 65, no. 8, pp. 15861588.

91. Post, V., White, P.A., and Hall, R.M., Evolution of AbaR-type genomic resistance islands in multiply antibiotic-resistant Acinetobacter baumannii, J. Antimicrob. Chemother., 2010, vol. 65, pp. 1162-1170.

92. Turton, J.F., Kaufmann, M.E., Gill, M.J., Pike, R., Scott, P.T., Fishbain, J., Craft, D., Deye, G., Riddell, S., Lindler, L.E., and Pitt, T.L., Comparison of Acinetobacter baumannii isolates from the United Kingdom and the United States that were associated with repatriated casualties of the Iraq conflict, J. Clin. Microbiol., 2006, vol. 44, pp. 2630-2634.
93. Morgan, D.J., Weisenberg, S.A., Augenbraun, M.H., Calfee, D.P., Currie, B.P., Furuya, E.Y., Holzman, R., Montecalvo, M.C., Phillips, M., Polsky, B.A., and Sepkowitz, K., Multidrug-resistant Acinetobacter baumannii in New York city-10 years into the epidemic, Infect. Control Hosp. Epidemiol., 2009, vol. 30, pp. 196-197.

94. Vila, J., Marcos, A., Marco, F., Abdalla, S., Vergara, Y., Reig, R., Gomez-Lus, R., and Jimenez de Anta, T., In vitro antimicrobial production of beta-lactamases, aminoglycoside-modifying enzymes, and chloramphenicol acetyltransferase by and susceptibility of clinical isolates of Acinetobacter baumannii, Antimicrob. Agents Chemother., 1993, vol. 37, pp. 138-141.

95. Zhao, W.H. and Hu, Z.Q., Acinetobacter: A potential reservoir and dispenser for $\beta$-lactamases, Crit. Rev. Microbiol., 2012, vol. 38, pp. 30-51.

96. Rodriguez-Martinez, J.M., Nordmann, P., Ronco, E., Bonomo, R.A., Wang, H.N., and Yohei Doi, Extended-spectrum cephalosporinase in Acinetobacter baumannii, Antimicrob. Agents Chemother., 2010, vol. 54, pp. 3484-3488.

97. Poirel, L. and Nordmann, P., Genetic structures at the origin of acquisition and expression of the carbapenemhydrolyzing oxacillinase gene blaOXA-58 in Acinetobacter baumannii, Antimicrob. Agents Chemother., 2006, vol. 50, pp. 1442-1448.

98. Héritier, C., Poirel, L., Lambert, T., and Nordmann, P., Contribution of acquired carbapenem hydrolyzing oxacillinases to carbapenem resistance in Acinetobacter Antimicrob. Agents Chemother., 2005, vol. 49, no. 8, pp. 3198-3202.

99. Al-Sweih, N.A., Al-Hubail, M.A., and Rotimi, V.O., Emergence of tigecycline and colistin resistance in Acinetobacter species isolated from patients in $\mathrm{Ku}-$ wait hospitals, J. Chemother., 2011, vol. 23, no. 1, pp. $13-16$.

100. Bonnin, R.A., Poirel, L., Naas, T., Pirs, M., Seme, K., Schrenzel, J., and Nordmann, P., Dissemination of New Delhi metallo- $\beta$-lactamase-1-producing Acinetobacter baumannii in Europe, Clin. Microbiol. Infect., 2012, vol. 18, no. 9, p. E362-5.

101. Bogaerts, P., Rezende de Castro, R., Roisin, S., Deplano, A., Huang, T.D., Hallin, M., Denis, O., and Glupczynski, Y., Emergence of NDM-1-producing Acinetobacter baumannii in Belgium, J. Antimicrob. Chemother., 2012, vol. 67, no. 6, pp. 1552-1553.

102. Robledo, I.E., Aquino, E.E., Santé, M.I., Santana, J.L., Otero, D.M., León, C.F., and Vázquez, G.J., Detection of KPC in Acinetobacter spp. in Puerto Rico, Antimicrob. Agents Chemother., 2010, vol. 54, pp. 13541357.

103. Ramírez, M.S., Piñeiro, S., and Centrón, D., Novel insights about class 2 integrons from experimental and genomic epidemiology, Antimicrob. Agents Chemother., 2010, vol. 54, pp. 699-706.

104. McGowan, J.E., Jr., Resistance in non-fermenting Gram-negative bacteria: Multidrug resistance to the maximum, Am. J. Med., 2006, vol. 119, no. 6, Suppl. 1, pp. S29-S36. 
105. Wong, E.W., Yusof, M.Y., Mansor, M.B., Anbazhagan, D., Ong, S.Y., and Sekaran, S.D., Disruption of ade $B$ gene has a greater effect on resistance to meropenems than adeA gene in Acinetobacter spp. isolated from University Malaya Medical Centre, Singapore Med. J., 2009, vol. 50, pp. 822-826.

106. Bonnin, R.A., Potron, A., Poirel, L., and Dunman, P.M., PER-7, an extended spectrum beta-lactamase with increased activity toward broad spectrum cephalosporins in Acinetobacter baumannii, Antimicrob. Agents Chemother., 2011, vol. 55, no. 5, pp. 2424-2427.

107. Naas, T., Poirel, L., and Nordmann, P., Minor extended-spectrum $\beta$-lactamases, Clin. Microbiol. Infect., 2008, vol. 14, pp. 42-52.

108. Shakil, S. and Khan, A.U., Detection of CTX-M-15producing and carbapenem-resistant Acinetobacter baumannii strains from Urine from an Indian hospital, J. Chemother., 2010, vol. 22, pp. 324-327.

109. Limansky, A.S., Mussi, M.A., and Viale, A.M., Loss of a 29-kilodalton outer membrane protein in Acinetobacter baumannii is associated with imipenem resistance, J. Clin. Microbiol., 2002, vol. 40, pp. 47764778 .

110. Gribun, A., Nitzan, Y., Pechatnikov, I., Hershkovits, G., and Katcoff, D.J., Molecular and structural characterization of the $H M P-A B$ gene encoding a pore-forming protein from a clinical isolate of Acinetobacter baumannii, Curr. Microbiol., 2003, vol. 47, no. 5, pp. 434-443.

111. Coyne, S., Rosenfeld, N., Lambert, T., Courvalin, P., and Périchon, B., Over expression of resistance-nodulation-cell division pump AdeFGH confers multidrug resistance in Acinetobacter baumannii, Antimicrob. Agents Chemother., 2010, vol. 54, no. 10, pp. 43894393.

112. Damier-Piolle, L., Magnet, S., Brémont, S., Lambert, T., and Courvalin, P., AdeIJK, a resistance nodulation-cell division pump effluxing multiple antibiotics in Acinetobacter baumannii, Antimicrob. Agents Chemother., 2008, vol. 52, no. 2, pp. 557-562.

113. Magnet, S., Courvalin, P., and Lambert, T., Resistance-nodulation cell division-type efflux pumps involved in aminoglycoside resistance in Acinetobacter baumannii strain BM4454, Antimicrob. Agents Chemother., 2001, vol. 45, pp. 3375-3380.

114. Roca, I., Espinal, P., Marti, S., and Vila, J., First identification and characterization of an AdeABC like efflux pump in Acinetobacter genomospecies 13TU, Antimicrob. Agents Chemother., 2011, vol. 55, pp. 12851286.

115. Dupont, M., Pagès, J.M., Lafitte, D., Siroy, A., and Bollet, C., Identification of an OprD homologue in Acinetobacter baumannii, J. Proteome Res., 2005, vol. 4, no. 6, pp. 2386-2390.

116. Cho, Y.J., Moon, D.C., Jin, J.S., Choi, C., Lee, Y.C., and Lee, J.C., Genetic basis of resistance to aminoglycosides in Acinetobacter spp. and spread of armA in Acinetobacter baumannii sequence group 1 in Korean hospitals, Diagn. Microbiol. Infect. Dis., 2009, vol. 64, no. 2, pp. $185-190$.
117. Smith, C.A. and Baker, E.N., Aminoglycoside antibiotic resistance by enzymatic deactivation, Curr. Drug Targets: Infect. Disord., 2002, vol. 2, pp. 1431-1460.

118. Nemec, A., Dolzani, L., Brisse, S., van den Broek, P., and Dijkshoorn, L., Diversity of aminoglycoside-resistance genes and their association with class 1 integrons among strains of pan-European Acinetobacter baumannii clones, J. Med. Microbiol., 2004, vol. 53, pp. 1233-1240.

119. Fàbrega, A., Madurga, S., Giralt, E., and Vila, J., Mechanism of action of and resistance to quinolones, Microb. Biotechnol., 2009, vol. 2, no. 1, pp. 40-61.

120. Vila, J., Ruiz, J., Goni, P., and Jimenez de Anta, T., Quinolone resistance mutations in the topoisomerase IV parC gene of Acinetobacter baumannii, J. Antimicrob. Chemother., 1997, vol 39, pp. 757-762.

121. Seward, R.J. and Towner, K.J., Molecular epidemiology of quinolone resistance in Acinetobacter spp., Clin. Microbiol. Infect., 1998, vol. 4, pp. 248-254.

122. Falagas, M.E. and Kasiakou, S.K., Colistin: The revival of polymyxins for the management of multidrug-resistant Gram-negative bacterial infections, Clin. Infect. Dis., 2005, vol 40, no. 9, pp. 1333-1341.

123. Moffatt, J., Harper, M., Harrison, P., Hale, J.D., Vinogradov, E., Seemann, T., Henry, R., Crane, B., St. Michael, F., Cox, A.D., Adler, B., Nation, R.L., Li, J., and Boyce, J.D., Colistin resistance in Acinetobacter baumannii is mediated by complete loss of lipopolysaccharide production, Antimicrob. Agents Chemother., 2010, vol. 54, pp. 4971-4977.

124. Adams, M.D., Nickel, G.C., Bajaksouzian, S., Lavender, H., Murthy, A.R., Jacobs, M.R., and Bonomo, R.A., Resistance to colistin in Acinetobacter baumannii associated with mutations in the PmrAB two-component system, Antimicrob. Agents Chemother., 2009, vol. 53, no. 9, pp. 3628-3634.

125. Piddock, L.J., Clinically relevant chromosomally encoded multidrug resistance efflux pumps in bacteria, Clin. Microbiol. Rev., 2006, vol. 19, pp. 382-402.

126. Yoon, E., Balloy, V., Fiette, L., Chignard, M., Courvalin, P., and Grillot-Courvalin, C., Contribution of the Ade resistance-nodulation-cell division-type efflux pumps to fitness and pathogenesis of Acinetobacter baumannii, mBio, 2016, vol. 7, no. 3, p. e00697-16.

127. Marchand, I., Damier-Piolle, L., Courvalin, P., and Lambert, T., Expression of the RND-type efflux pump AdeABC in Acinetobacter baumannii is regulated by the AdeRS two-component system, Antimicrob. Agents Chemother., 2004, vol. 48, pp. 3298-3304.

128. Ruiz, M., Marti, S., Fernandez-Cuenca, F., Pascual, A., and Vila, J., High prevalence of carbapenem hydrolyzing oxacillinases in epidemiologically related and unrelated Acinetobacter baumannii clinical isolates in Spain, Clin. Microbiol. Infect., 2007, vol. 13, pp. 11921198.

129. Fournier, P.E., Vallenet, D., Barbe, V., Audic, S., Ogata, H., Poirel, L., Richet, H., Robert, C., Mangenot, S., Abergel, C., Nordmann, P., Weissenbach, J., Raoult, D., and Claverie, J.M., Comparative 
genomics of multidrug resistance in Acinetobacter baumannii, PLoS Genet., 2006, vol. 2, no. 1, p. e7.

130. Sugawara, E. and Nikaido, H., Properties of AdeABC and AdeIJK efflux systems of Acinetobacter baumannii compared with those of the AcrAB-TolC system of Escherichia coli, Antimicrob. Agents Chemother., 2014, vol. 58, pp. 7250-7257.

131. Roca, I., Marti, S., Espinal, P., Martínez, P., Gibert, I., and Vila, J., CraA, a major facilitator super family efflux pump associated with chloramphenicol resistance in Acinetobacter baumannii, Antimicrob. Agents Chemother., 2009, vol. 53, pp. 4013-4014.

132. Rajamohan, G., Srinivasan, V.B., and Gebreyes, W.A., Molecular and functional characterization of a novel efflux pump, AmvA, mediating antimicrobial and disinfectant resistance in Acinetobacter baumannii, Antimicrob. Agents Chemother., 2010, vol. 65, pp. 19191925.

133. Vila, J., Martí, S., and Sánchez-Céspedes, J., Porins, efflux pumps and multidrug resistance in Acinetobacter baumannii, J. Antimicrob. Chemother., 2007, vol. 59, pp. $1210-1215$.
134. Su, X.Z., Chen, J., Mizushima, T., Kuroda, T., and Tsuchiya, T., AbeM, an $\mathrm{H}^{+}$-coupled Acinetobacter baumannii multidrug efflux pump belonging to the MATE family of transporters, Antimicrob. Agents Chemother., 2005, vol. 49, pp. 4362-4364.

135. Srinivasan, V.B., Rajamohan, G., and Gebreyes, W.A., Role of AbeS, a novel efflux pump of the SMR family of transporters, in resistance to antimicrobial agents in Acinetobacter baumannii, Antimicrob. Agents Chemother., 2009, vol. 53, pp. 5312-5316.

136. Tang, S., Apisarnthanarak, A., and Hsu, L.Y., Mechanisms of $\beta$-lactam antimicrobial resistance and epidemiology of major community and healthcare-associated multidrug-resistant bacteria, Adv. Drug Delivery Rev., 2014, vol. 30, pp. 3-13.

137. Levin, A.S., Levy, C.E., Manrique, A.E., Medeiros, E.A., and Costa, S.F., Severe nosocomial infections with imipenem-resistant Acinetobacter baumannii treated with ampicillin/sulbactam, Int. J. Antimicrob. Agents, 2003, vol. 21, no. 1, pp. 58-62. 